\title{
Real-time 3D-echocardiography of the right ventricle-paediatric reference values for right ventricular volumes using knowledge-based reconstruction: a multicentre study
}

\author{
Ulrike Herberg $^{1 \#}$, Florentina Smit ${ }^{1 \#}$, Christian Winkler ${ }^{1}$, Robert Dalla-Pozza $^{2}$, Johannes Breuer ${ }^{1}$, \\ Kai Thorsten Laser ${ }^{3}$
}

${ }^{1}$ Department of Paediatric Cardiology, University of Bonn, ELKI, Venusberg Campus 1, Germany; ${ }^{2}$ Department of Paediatric Cardiology and Paediatric Intensive Care, Ludwig Maximilians University, Medical Hospital of the University of Munich, Munich, Germany; ${ }^{3}$ Department of Congenital Heart Defects, Heart and Diabetes Centre North Rhine Westphalia, Ruhr University Bochum, Bad Oeynhausen, Germany

"These authors contributed equally to this work.

Correspondence to: Ulrike Herberg, MD. Department of Paediatric Cardiology, University of Bonn, ELKI, Gebd. 30, Venusberg-Campus 1, 53127 Bonn, Germany. Email: ulrike.herberg@ukbonn.de.

Background: Real-time 3D echocardiography is a promising method for non-invasive assessment of right ventricular performance in children with congenital heart disease. Volume quantification using knowledgebased reconstruction (KBR) enables the calculation of right ventricular dimensions by matching endocardial landmarks with a reference library of right ventricular shapes. However, paediatric reference values for volumes based on KBR are missing. Aim of this study was to establish reference values for right ventricular volumes in a large paediatric population using 3D echocardiography and KBR.

Methods: In a multicentre prospective-design study, 545 healthy children and adolescents (age range, 1 day to 216 months) underwent 3D echocardiography of the right ventricle using two different vendors (iE33, Philips or Vivid 7, GE). Volume analysis was performed by a semiautomatic quantification software (VMS, Ventripoint Diagnostics Ltd., Washington, US). Reference centiles were computed using Cole's LMS method and the gamlss package in R. For vendor comparison, 3D datasets were recorded subsequently in 20 subjects using both ultrasound devices.

Results: 3D datasets of 406/545 (74.5\%) subjects provided an adequate image quality. Right ventricular volumes had a significant association with age, body size and sex. We created sex-specific percentiles indexed to body surface area (BSA). Intra- and interobserver-variation for all volume calculations were excellent with intraclass correlation coefficients (ICCs) between 0.973-0.998. Agreement of both vendors showed slightly higher end-diastolic and stroke volumes (bias \pm standard deviation $2.2 \% \pm 6.8 \%$ respectively $4.5 \% \pm 8.1 \%$ ) and smaller end-systolic volumes $(-0.9 \pm 10.3 \%)$ using Philips datasets.

Conclusions: Calculation of ventricular volumes by KBR allows reliable non-invasive assessment of right ventricular volumes with excellent intra- and interobserver variations. The calculated percentiles based on a large paediatric population serve as a reference and may facilitate the use of real-time 3D echocardiography for the analysis of right ventricular size and function.

Keywords: 3D echocardiography; reference values; children; right ventricle; volumetry; knowledge-based reconstruction $(\mathrm{KBR})$

\footnotetext{
$\wedge$ ORCID: 0000-0002-9386-0258.
} 
Submitted Oct 17, 2020. Accepted for publication Jan 29, 2021.

doi: 10.21037 /qims-20-1155

View this article at: http://dx.doi.org/10.21037/qims-20-1155

\section{Introduction}

The accurate assessment of right ventricular (RV) volume and function is of fundamental importance for clinical decision making and follow-up in paediatric cardiology. Both, volume, and function, have been shown to be major indicators of symptoms and survival in patients with acquired and congenital heart disease (CHD) such as corrected tetralogy of Fallot, hypoplastic left heart syndrome or pulmonary hypertension (1-6). Unfortunately, as a result of its complex shape and location behind the sternum exact echocardiographic assessment is challenging.

While cardiac magnetic resonance (CMR) imaging is currently the gold standard for RV quantification (7), echocardiography is more accessible in a clinical setting, less time consuming and comparatively cheaper. Echocardiography rarely requires sedation even in young children and has hardly any contraindications. Two-dimensional echocardiography (2DE), however, is not reliable in the estimation of $\mathrm{RV}$ size and function (8-11). The complex crescent shape of the right ventricle cannot be visualised in single two-dimensional views. Real-time three-dimensional echocardiography (RT3DE) has emerged as a promising clinical alternative, being more accurate than 2DE (6,8-12). Current post-processing software using semiautomatic border tracing may underestimate RV volumes and ejection fraction (EF) $(13,14)$. Therefore, knowledge-based reconstruction (KBR) has been developed on a model-based approach to overcome some of the limitations of endocardial border tracing. In an individual dataset, distinct anatomical structures of the right ventricle are identified in different planes. These anatomic landmarks are used to create a three-dimensional reconstruction of the RV cavity with the aid of a of a database catalogue. The catalogue includes various geometrical shapes of the RV which exist in the normal heart as well as various forms of CHD $(15,16)$. Ventricular dimensions are then calculated from the reconstruction. This method has been evaluated with good results for CMR, 2DE, and RT3DE including both healthy subjects without structural or functional anomalies and such with CHD and has been shown to improve the computation of the right ventricle (15-20). For the quantification of volumes in RT3D datasets KBR has been validated with CMR and has been shown to be accurate, reliable, and reproducible (15).
Reference values for RV volumes and ejection fraction are essential for accurate detection and evaluation of pathologies. The aim of this study was to establish reference values for right ventricular volumes in a large paediatric population using RT3DE and KBR.

\section{Methods}

\section{Study group}

In a multicentre prospective design 545 children and adolescents were enrolled to undergo RT3DE of the RV. The group consisted of 282 (52\%) boys and 263 (48\%) girls. The age range of the whole group was 1 day to 216 months with a median age of 90.0 months. All subjects were in sinus rhythm, had normal results on standard echocardiography, and did not participate in competitive sport activities. Body weight and height were measured and body surface area (BSA) was calculated by the Haycock formula (21).

The examinations were performed at three centres within Germany after standardisation of the acquisition procedure and operator training (21). The accuracy of the different imaging equipment and platforms was verified using calibrated phantoms. The data were subsequently quantified in a core-laboratory at one centre.

The study was approved by the local ethics institutional review committees (Registration No. 226/06 and No. 20/10) and by the representative boards of all participating centres and conformed to the principles of the Declaration of Helsinki as well as German law. Informed written consent was obtained from all participants and/or their legal guardians before participation.

\section{RT3DE image acquisition}

RT3DE was performed using two different vendors: the iE33 System with an X 5-1 or X7-2 transducer (Philips Medical Systems, Best, The Netherlands) or a Vivid 9 System with a V4 transducer (GE Medical Systems, Milwaukee, WI). To depict the entire right ventricle individually apical projections as well as a modified apical view were acquired by angulating the probe upward and toward the left, starting from the position of a standard five- 
chamber view, until inflow, outflow, and apex of the right ventricle became visible (15). Full-volume data sets were acquired with a stable transducer position. Older children able to cooperate were asked to perform an end-expiratory breath-hold during acquisition to avoid respiratory motion. Children unable to hold their breath were examined under spontaneous breathing. The mean temporal resolution was 27 volumes/sec (standard deviation SD: \pm 8.5 volumes $/ \mathrm{sec}$ ) with a mean volume rate per heart beat of 16 (range, 7-35). For a subset of randomly selected subjects, RT3DE scans were acquired during the same session with an $\mathrm{iE} 33$ system as well as a Vivid 9 system, without significant change in heart rate or blood pressure in the subjects, and compared for vendor comparison.

\section{Evaluation of RT3DE data}

For each subject the RT3DE volume data set of the best image quality was imported to the Ventripoint Medical System (VMS) software (version 1.2.6905.4788, Ventripoint Diagnostics Ltd., Bellevue, WA) and the tool "Right Ventricle" for healthy right ventricles was used for the further computation.

End-systolic and end-diastolic frames were identified in the four-chamber view as the smallest and largest RVcavity respectively in representative $2 \mathrm{DE}$ reformatted planes. The same end-systolic to end-diastolic interval was automatically applied to all other views in the same data set. A set of anatomic landmarks such as the pulmonary valve annulus, the tricuspid valve annulus, apex, interventricular septum, and RV endocardium were then plotted in the endsystolic and end-diastolic data sets. Endocardial landmarks were placed at the bases of trabeculae therefore including them into the RV cavity volumes. A minimum of 11 points were required to create a $3 \mathrm{D}$ model. The plotted anatomic landmarks and their 3D special coordinates were then transmitted to a remote server via a secure internet connection and a RV model was created using a knowledgebased reconstruction algorithm referring the plotted points against a catalogue of templates for hearts with normal shapes on the knowledge data base in VMS (Figure 1) (15).

The resulting $3 \mathrm{D}$ models could be superimposed on the original scan plains and the intersections inspected. In rare cases, where alignment between the surface of the $3 \mathrm{D}$ model and either the plotted points or the echocardiographic borders were not satisfactory, points were repositioned, removed, or added as required and the algorithm rerun.
The VMS software uses the 3D models to calculate the respective end-systolic and end-diastolic volumes as well as stroke volume and ejection fraction. The use of KBR for the calculation of RV volumes in 3DRT datasets method has already been systematically evaluated by our group (15).

\section{Statistical analysis and construction of centile curves}

RT3DE data were quantified by a single investigator (F.S). Intraobserver comparisons were performed with data from randomly selected individuals with the second quantification more than 4 weeks apart and blinded to the results of the first. Interobserver variability was assessed by a second investigator who was blinded to the previous results. All datasets were reanalysed using raw data, starting with the definition of end-diastole and end-systole and position of the landmarks. The correlation was expressed by the intraclass correlation coefficient (ICC) (SPSS version 22, SPSS, Inc., Chicago, IL) and for the assessment of the agreement Bland-Altman analysis was performed (Prism 6, GraphPad Software, Inc., La Jolla, CA). Pearsons correlation was used to correlate relevant continuous variables (Prism 6). For the construction of centile curves, we applied the LMS method by Cole and Green (22). We used the software environment $\mathrm{R}$ and the add-on package gamlss for the computation $(23,24)$. As response variable, we chose end-diastolic volume (EDV), end-systolic volume (ESV), stroke volume (SV), volumes indexed to BSA and obtained age dependent curves for each response variable. For the training of the curves, the gamlss package allows to vary the degrees of freedom for the penalized splines of the parameters L (Box-Cox power), M (median) and S (coefficient of variation).

\section{Results}

The clinical characteristics of our study population are presented in Table 1. From a total of 545 individuals 406 could be included in the study, resulting in feasibility of $74.5 \%$. The main reasons for the exclusion of data were incomplete depiction of the RV, insufficient image quality such as indistinct endocardial borders or breathing artefacts $(n=88)$, incomplete demographic data $(n=3)$ or $3 \mathrm{D}$ datasets which were not retrievable $(\mathrm{n}=8)$. The age and sex distributions are shown in Figure 2. Of 406 datasets, 94 were acquired with a GE ultrasound machine. As recently published by our group, image analysis for RT3DE data sets 

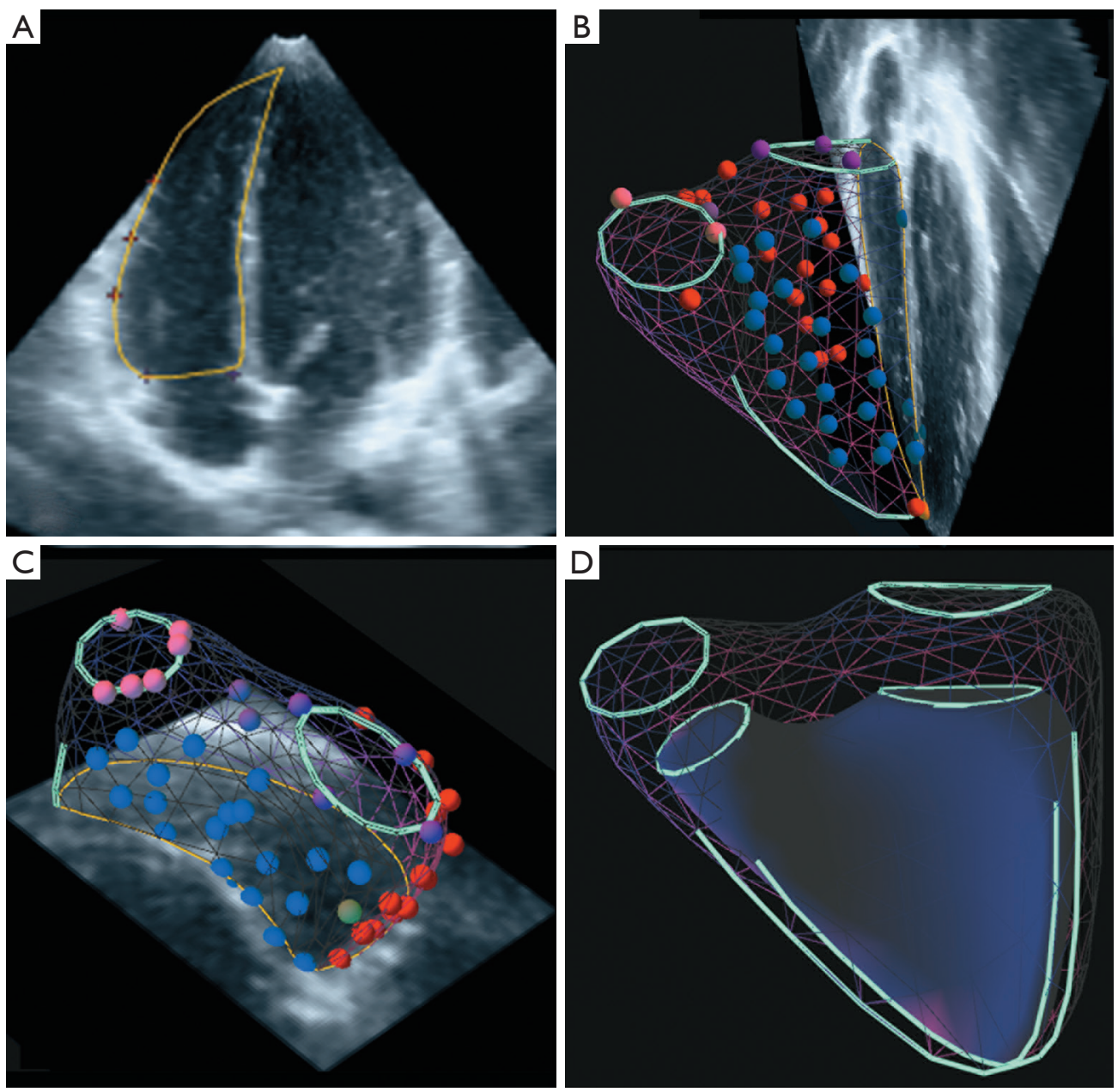

Figure $13 \mathrm{D}$ right ventricular models based on the Knowledge-Based Reconstruction after setting of anatomical landmarks. (A) Contour model of the RV border (yellow line) superimposed into a 4-chamber view reconstructed from the RT3D full volume, crosses depict the previous placement of landmarks. (B) 3D-model including mesh structure, points, outlines, and borders in a 4-chamber view. (C) Same presentation as b in a short axis view. (D) Combined view of outlines and borders of the 3D-model in end systole (blue) and end diastole (purple mesh). Colour coding: red: RV endocardium, blue: interventricular septum, pink: pulmonic annulus, purple: tricuspid annulus, yellow: apex.

required a mean time of $4 \min (15)$.

\section{Reproducibility}

The results of intraobserver and interobserver comparisons are shown in Table 2 and Figures S1,S2. Intraobserver agreement (Table 2, Figure S1) was remarkably good, especially for ESV and EDV resulting in ICCs of 0.999 for both parameters and minimal bias with low limits of agreement (LOA). Interobserver variation (Table 2, Figure S2) was slightly higher with the best agreement again for ESV (ICC 0.995) and EDV (ICC 0.996). The second observer's evaluations resulted in generally larger volumes leading to a distinct bias of up to $4.1 \%$ between the observers.

\section{Vendor comparison}

The comparison of volumes calculated from RT3DE acquired from the same individual both using an iE33 and a Vivid 9 ultrasound system (Table 3, Figure S3) likewise showed good results with ICCs of 0.986, 0.992, 0.991 and 0.927 for ESV, EDV, SV and ejection fraction (EF) respectively. Evaluation of scans acquired with the iE33 system resulted in smaller 
Table 1 Demographic data of study population

\begin{tabular}{lccc}
\hline Variables & All subjects & Subjects included in study & Subjects not included in study \\
\hline Total number & 545 & $406(74 \%)$ & $139(26 \%)$ \\
Female gender & $263(48 \%)$ & $193(48 \%)$ & $70(50 \%)$ \\
Age mean \pm SD (months) & $91.2 \pm 63.4$ & $95.6 \pm 63.0$ & $78.3 \pm 62.8$ \\
Age range (months) & $0.03-216$ & $0.03-216$ & $0.6-210$ \\
Weight mean \pm SD $(\mathrm{kg})$ & $29.7 \pm 19.8$ & $30.6 \pm 19.6$ & $26.9 \pm 19.9$ \\
Weight range $(\mathrm{kg})$ & $1.9-93$ & $1.9-93$ & $4-86$ \\
Height mean \pm SD $(\mathrm{cm})$ & $123 \pm 36.8$ & $125 \pm 36.8$ & $116 \pm 36.0$ \\
Height range $(\mathrm{cm})$ & $45-194$ & $45-194$ & $54-190$ \\
\hline
\end{tabular}

There were no significant differences between the included and not included groups. SD, standard deviation.

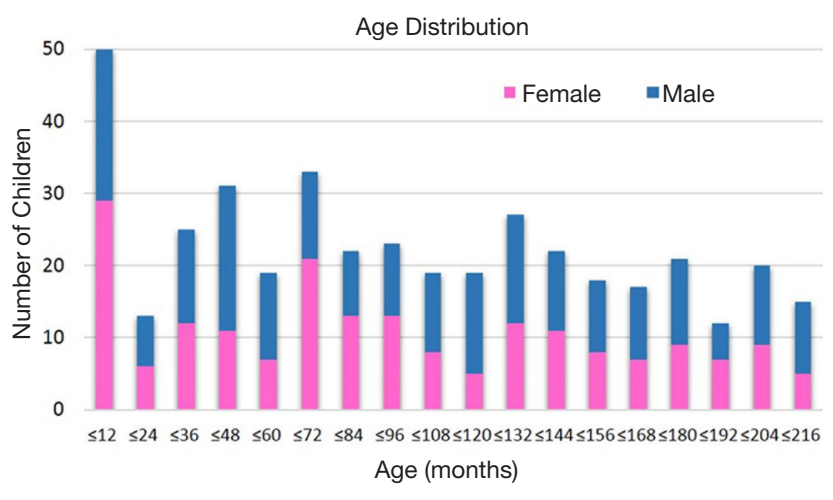

Figure 2 Sex and age distribution of the cohort included.

end-systolic volumes (bias $\pm \mathrm{SD}:-1.1 \pm 4.6 \mathrm{~mL}$ ) but larger enddiastolic volumes $(0.7 \pm 7.1 \mathrm{~mL})$ and therefore larger stroke volumes (bias $1.7 \% \pm 4.3 \%$ ) compared to scans acquired with the Vivid 9 system.

\section{Reference values (Figures 3,4)}

$\mathrm{RV}$ volumes correlate with age $(\mathrm{r}=0.913-0.938)$, weight $(\mathrm{r}=0.953-0.973)$, height $(\mathrm{r}=0.913-0.939)$ and BSA $(\mathrm{r}=0.952-$ 0.975). The EF showed little correlation with these parameters ( $\mathrm{r}=-0.0999$ to -0.129$)$. Comparison between the male and female study population showed significant differences in RV volumes indexed for BSA $(\mathrm{P}<0.001)$ with significant larger volumes being observed in boys (Table 4 , differences $>9 \%$ ). Consequently, separate centile curves were created for both sexes and are presented as absolute age-dependent values, as well as volumes indexed to BSA (Figures 3,4). Figure S4 depict sex-specific centile curves related to height. Significant sex differences were not found concerning the EF.

\section{Discussion}

This prospective multicentre study provides gender-specific paediatric reference values for RV volumes and ejection fraction in a large population of healthy children without structural or functional anomaly from birth to 18 years of age using state-of-the-art RT3DE and KBR.

The main findings of this study are the sex differences in $\mathrm{RV}$ volumes, which seem to be present even in very young children and a strong correlation of $\mathrm{RV}$ volumes with demographic and anthropometric parameters.

In addition, we found KBR to be a reliable, vendorindependent, and reproducible post processing method for the quantification of right ventricular volumes acquired by 3DRTE.

\section{Maturational changes and gender differences in $R V$ volumes}

Cardiac measures are known to be related to body size in the maturating child. The continuous growth and hormone status before, during and after puberty influence the chamber sizes (25-27). In cardiovascular medicine, it has been shown helpful to adequately scale RV volumetric parameters to body size (28). Our own findings indicate a strong correlation of RV volumes with BSA and match with findings by current studies. Therefore, we present our ventricular volumes indexed for BSA with the additional benefits of better visualising a large volume range of 1.1 to 
Table 2 Intra- and interobserver variability expressed as relative and absolute mean \pm SD, LOA (Bland-Altman analysis), and ICCs with 95\% CI

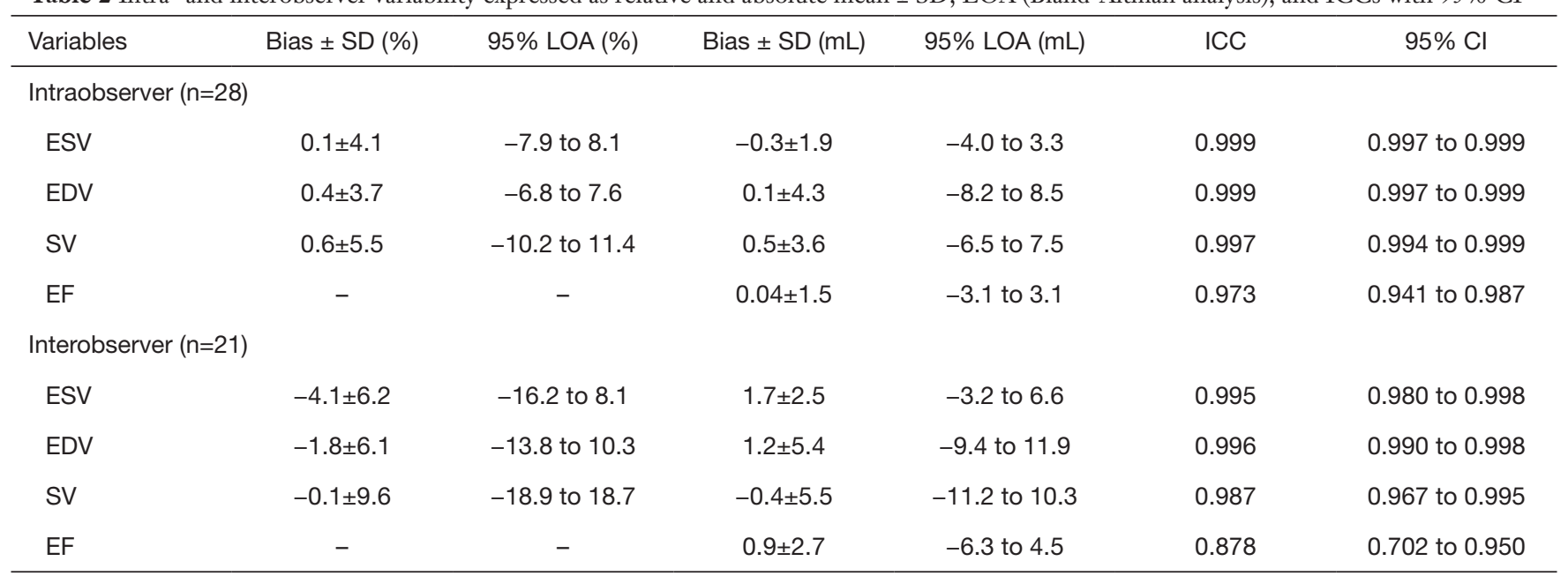

LOA, limits of agreement; ICC, intraclass correlation coefficient.

Table 3 Vendor comparison expressed as relative and absolute mean \pm SD, LOA (Bland-Altman analysis), ICCs with 95\% CI, and Philips (iE 33) vs. GE (Vivid)

\begin{tabular}{lcccccc}
\hline Vendor-comparison $(\mathrm{n}=20)$ & Bias \pm SD $(\%)$ & $95 \%$ LOA $(\%)$ & Bias \pm SD $(\mathrm{mL})$ & $95 \%$ LOA $(\mathrm{mL})$ & ICC & $95 \%$ Cl \\
\hline ESV & $-0.9 \pm 10.3$ & -21.0 to 19.2 & $-1.1 \pm 4.6$ & -10.1 to 8.0 & 0.986 & 0.965 to 0.995 \\
EDV & $2.2 \pm 6.8$ & -11.1 to 15.5 & $0.7 \pm 7.1$ & -13.2 to 14.6 & 0.992 & 0.980 to 0.997 \\
SV & $4.5 \pm 8.1$ & -11.4 to 20.3 & $1.7 \pm 4.3$ & -6.6 to 10.1 & 0.991 & 0.976 to 0.996 \\
EF & $2.4 \pm 5.0$ & -7.4 to 12.2 & $1.4 \pm 2.9$ & -4.2 to 7.0 & 0.927 & 0.815 to 0.971 \\
\hline
\end{tabular}

$208.5 \mathrm{~mL}$ and comparability with former studies (29). Rather than presenting comparisons by arbitrary age categories we aimed to deliver centile curves using Coles LMS method (22), which graphically present the distribution of a parameter over the whole age range of the sample.

Studies about sex differences in paediatric RV volumes are relatively scarce. However, our findings are in agreement with a number of previous studies. Sarikouch et al. (30) found that sex differences are important when treating children and adults with CHD. In another study, the same group (29) found significant sex differences in RV volumes indexed to BSA and height for 99 subjects aged 8 to 20 years using cardiac MRI. They concluded that volumes are higher in boys than girls. Interestingly, the observed sex difference was noticeable but not statistically significant, when only the younger children aged 8 to 15 years were analysed. The larger sample size and younger subjects of our study may account for the sex difference being more pronounced even in the younger age groups. Sex differences in adult RV volumes have been well observed (31-33), yet, maybe more surprisingly studies on other RV parameters such as valve diameters also suggest the existence of sex differences even before puberty $(34,35)$.

\section{Knowledge based reconstruction}

The KBR method has been evaluated with good results to quantify $\mathrm{RV}$ volumes from sequential 2DE datasets for healthy right ventricles. Also, various pathologies such as Tetralogy of Fallot, ventricular septal defects, transposition of great arteries after palliative surgery and pulmonary hypertension have been analysed with the KBR method (16-20,36-38). In combination with RT3DE it also compares favourably to other RT3DE software, usually based on semiautomatic border tracing in accuracy and reproducibility $(15,39)$. Difficult border delineation due to blurring of the endocardium has led to systematic underestimation of RV volumes using border tracking. The underestimation was found to be more pronounced in larger or irregular right ventricles, such as in patients 

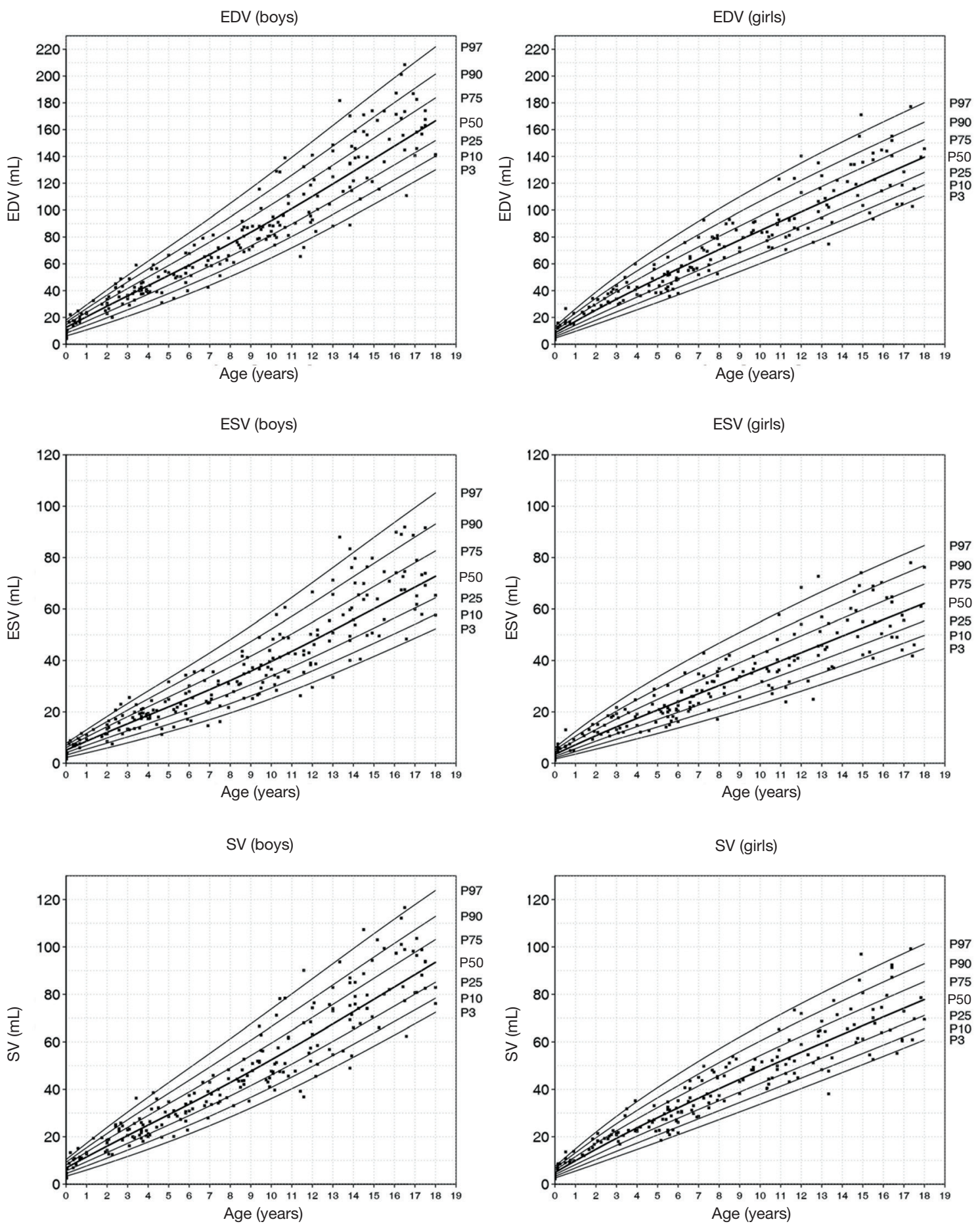

Figure 3 Gender-specific percentiles for with EDV, ESV, and SV in relation to age. $\mathrm{P}$ indicates the percentile value, e.g., P50 = 50th percentile value. EDV, end-diastolic volumes; ESV, end-systolic volumes; SV, stroke volume. 

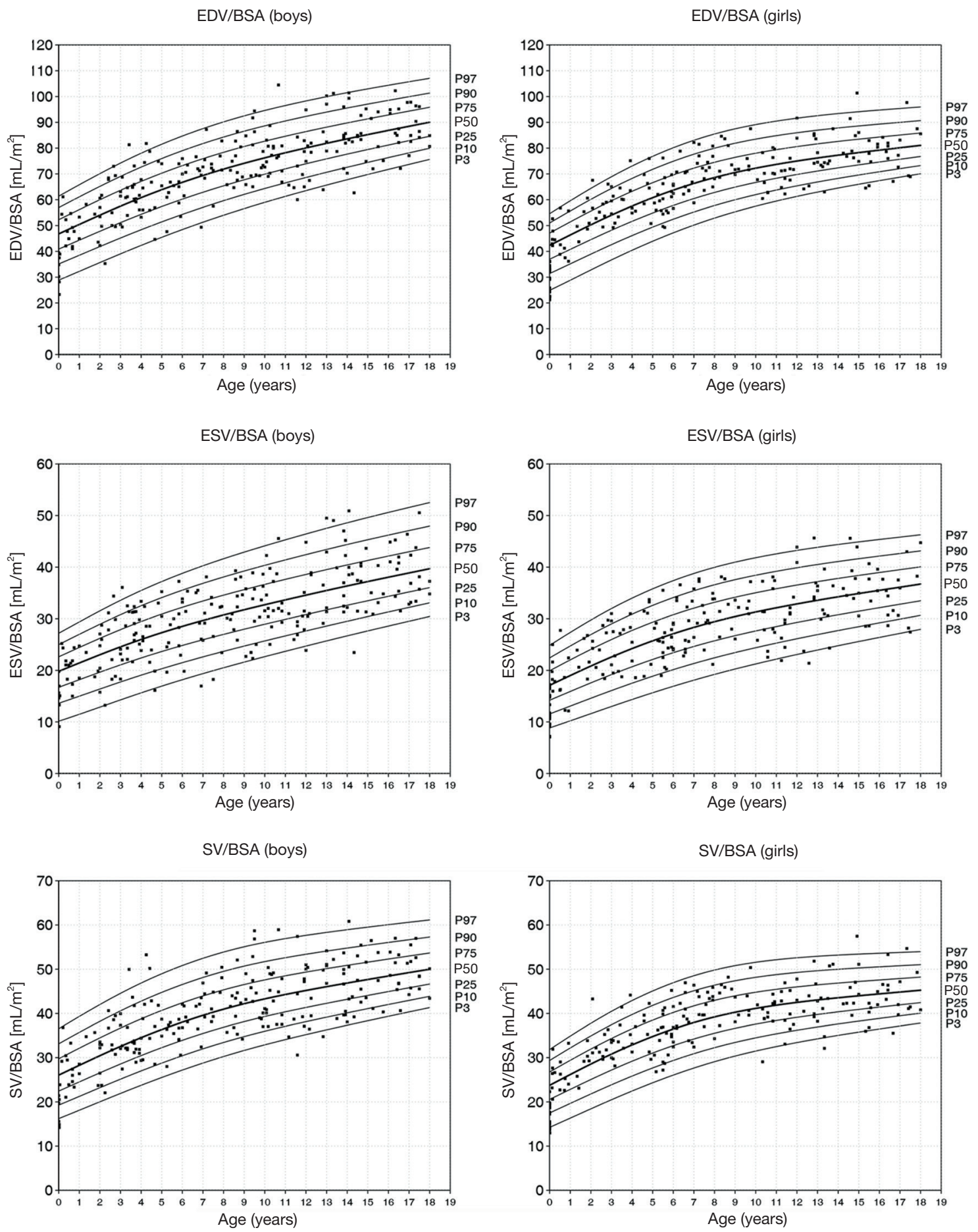

Figure 4 Gender-specific percentiles for with EDV, ESV, and SV indexed to BSA in relation to age. P indicates the percentile value, e.g., $\mathrm{P} 50=50$ th percentile value. 
Table 4 Effect of gender on RV-Volumes indexed for body surface area and EF

\begin{tabular}{|c|c|c|c|c|}
\hline Variables & ESV/BSA $\left(\mathrm{mL} / \mathrm{m}^{2}\right)$ & $\mathrm{EDV} / \mathrm{BSA}\left(\mathrm{mL} / \mathrm{m}^{2}\right)$ & $\mathrm{SV} / \mathrm{BSA}\left(\mathrm{mL} / \mathrm{m}^{2}\right)$ & $\mathrm{EF}(\%)$ \\
\hline Boys $(n=213)$ & $30.4 \pm 8.1$ & $70.5 \pm 16.0$ & $40.1 \pm 9.2$ & $56.9 \pm 4.9$ \\
\hline Difference (\%) & 9.3 & 9.1 & 9.1 & 0.4 \\
\hline Significance, $\mathrm{P}$ & 0.0008 & 0.0001 & 0.0001 & 0.709 \\
\hline
\end{tabular}

Volumes and ejection fraction expressed as mean \pm SD. EDV, end diastolic volume; EF, ejection fraction; ESV, end systolic volume; SV, stroke volume.

with CHD (13). To avoid these issues, the KBR method allows the investigator to define anatomic RV landmarks, which are identified and verified on multiple 2D slices extracted from the RT3DE full volume (Figure 1). RV volumes are subsequently calculated using a reference database for representative normal and pathological RV shapes, taking into account the irregular shapes of diseased right ventricles. This approach intends to reduce the impact of reduced spatial resolution. In this regard, the drawbacks of conventional software might be overcome. Nevertheless, datasets with poor image quality, reduced spatial or temporal resolution or incomplete depiction of the complete right ventricular cavity cannot assessed by any software.

Our previous findings (15) suggest that the KBR method results in highly accurate and reproducible RV volumetry in both healthy and diseased individuals and positively compares with other approaches $(13,14,39)$.

In contrast to reports on software using semiautomatic contour finding algorithms $(21,40)$ image acquisition by different vendors did not have a significant impact on volumetric results. Inter-vendor variability was within the same range as inter-observer variability (41) (Figures S2,S3). This permits usage of reference centiles for RT3D datasets of both vendors. It seems reasonable that image quality seems far more relevant for calculation of ventricular volumes than the influence of different ultrasound machines.

\section{Clinical implications}

Differentiating physiological from pathological right ventricular sizes not only at one given time but also on longitudinal follow-up is of paramount importance in clinical decision making as well as for evaluation and follow-up after therapeutic interventions. The centiles obtained were established for the normal configurated right ventricle and can serve as reference values for conditions with a regular shaped right ventricle. These are found in pulmonary hypertension, atrial septal defect before and after closure, pulmonary stenosis, and pulmonary regurgitation, after arterial switch of transposition of great arteries, cardiomyopathy and after cardiac transplantation.

The percentiles provided by our study may be useful to detect pathological development of RV sizes and determine its scale while also providing a basis for further research concerning RV proportions in healthy individuals and such with heart disease. In the future, RT3DE may represent an alternative to CMR.

\section{Limitations}

Limited availability and high cost of CMR as well as the need for sedation in young children were some of the reasons preventing us from subjecting healthy young children in different ages to CMR examination. Therefore, we compared the results of our evaluations to CMR as a reference standard, as recently published by our group [Laser et al. (15)] with very good results. In addition, there are several studies comparing RT3DE to CMR measurements in children and adults $(13,42-44)$ generally showing $\mathrm{RV}$ volumes to be slightly underestimated by RT3DE. This bias should be taken into account when comparing measurements analysed with different modalities and highlight the need for separate sets of reference values for both methods. While high accuracy and good reproducibility are some of the advantages of $3 \mathrm{DE}$ and KBR, we cannot deny that the feasibility of $74.5 \%$ demonstrated in our study is comparatively low.

This may be caused in part by the larger number of very young children included in our study population who were unable to cooperate fully or hold their breath during examination and in part by our relatively rigorous criteria, applied to make sure poor quality datasets were excluded to 
increase the reliability of the resulting reference values.

Although an ideal sample size to calculate paediatric nomograms has not been established, the selected sample size should be as large as possible whilst still being feasible. Therefore, we conducted a multicentre study using up-todate $3 \mathrm{D}$ equipment and enrolled a large number of subjects, including a relatively high number of neonates and small children, which earlier studies tended to avoid. This very young age group is particularly important because of the rapid growth rate of the children and change in cardiac volumes.

The centiles obtained were established for the normal configurated right ventricle, conditions as atrial switch and tetralogy of Fallot with severe right ventricular dilatation can be evaluated by other shapes of the KBR library. In addition, normal values may vary depending on the ethnic population and therefore need to be adjusted for other ethnic groups.

\section{Conclusions}

Calculation of RV volumes in RT3DE datasets by KBR software is feasible. This method allows a reproducible and non-invasive evaluation of the volumetric data in paediatric cardiology.

The centile curves provided are based on a large sample size of healthy children and created in a multicentre approach using different ultrasound machines, state-ofthe-art RT3DE and a vendor independent KBR software. These age- and sex-specific references for right ventricular volumes and EF may be useful serving as reference values in clinical practice and research.

\section{Acknowledgments}

We acknowledge Ursula Manunzio for the acquisition of part of the 3D-datasets. We also want to thank Ute Baur (study nurse), Nicola Rieder, Anna Hoppe, Hannah Kulka and Sophie Peiseler (student assistants) for their support and Brigitte Peters (Department of Biometry and Medical Informatics, Otto-von-Guericke University, Magdeburg, Germany) for guidance of statistical analysis and Emma Raderschadt for editorial assistance.

A part of the results has been presented at oral presentation at the Annual Meeting of the German Association for Paediatric Cardiology 2015 and as moderated poster at the Annual Meeting of the Association for European Paediatric and Congenital Cardiology 2015.
Funding: This work was supported by Fördergemeinschaft Deutsche Kinderherzen, Bonn, Germany (Project No. W-BN/M/BAD-009/2009).

\section{Footnote}

Conflicts of Interest: All authors have completed the ICMJE uniform disclosure form (available at http://dx.doi. org/10.21037/qims-20-1155). Drs. UH and JB report grants from Kinderherzen, during the conduct of the study. The authors have no other conflicts of interest to declare.

Ethical Statement: The study was conducted in accordance with the Declaration of Helsinki (as revised in 2013). The study was approved by ethics board of the University of Bonn (Registration No. 226/06) and Bochum (No. 20/10): the registration number of ethics board) and informed consent was taken from all individual participants and their legal guardians before participation.

Open Access Statement: This is an Open Access article distributed in accordance with the Creative Commons Attribution-NonCommercial-NoDerivs 4.0 International License (CC BY-NC-ND 4.0), which permits the noncommercial replication and distribution of the article with the strict proviso that no changes or edits are made and the original work is properly cited (including links to both the formal publication through the relevant DOI and the license). See: https://creativecommons.org/licenses/by-nc-nd/4.0/.

\section{References}

1. Abman SH, Hansmann G, Archer SL, Ivy DD, Adatia I, Chung WK, Hanna BD, Rosenzweig EB, Raj JU, Cornfield D, Stenmark KR, Steinhorn R, Thebaud B, Fineman JR, Kuehne T, Feinstein JA, Friedberg MK, Earing M, Barst RJ, Keller RL, Kinsella JP, Mullen M, Deterding R, Kulik T, Mallory G, Humpl T, Wessel DL, American Heart Association Council on Cardiopulmonary CCP, Resuscitation, Council on Clinical C, Council on Cardiovascular Disease in the Y, Council on Cardiovascular R, Intervention, Council on Cardiovascular S, Anesthesia, the American Thoracic S. Pediatric Pulmonary Hypertension: Guidelines From the American Heart Association and American Thoracic Society. Circulation 2015;132:2037-99.

2. Knauth AL, Gauvreau K, Powell AJ, Landzberg MJ, Walsh EP, Lock JE, del Nido PJ, Geva T. Ventricular size and 
function assessed by cardiac MRI predict major adverse clinical outcomes late after tetralogy of Fallot repair. Heart 2008;94:211-6.

3. Bell A, Rawlins D, Bellsham-Revell H, Miller O, Razavi $\mathrm{R}$, Simpson J. Assessment of right ventricular volumes in hypoplastic left heart syndrome by real-time threedimensional echocardiography: comparison with cardiac magnetic resonance imaging. Eur Heart J Cardiovasc Imaging 2014;15:257-66.

4. Koestenberger M, Apitz C, Abdul-Khaliq H, Hansmann G. Transthoracic echocardiography for the evaluation of children and adolescents with suspected or confirmed pulmonary hypertension. Expert consensus statement on the diagnosis and treatment of paediatric pulmonary hypertension. The European Paediatric Pulmonary Vascular Disease Network, endorsed by ISHLT and D6PK. Heart 2016;102 Suppl 2:ii14-22.

5. Tretter JT, Friedberg MK, Wald RM, McElhinney DB. Defining and refining indications for transcatheter pulmonary valve replacement in patients with repaired tetralogy of Fallot: Contributions from anatomical and functional imaging. Int J Cardiol 2016;221:916-25.

6. Jone PN, Schafer M, Pan Z, Bremen C, Ivy DD. 3D echocardiographic evaluation of right ventricular function and strain: a prognostic study in paediatric pulmonary hypertension. Eur Heart J Cardiovasc Imaging 2018;19:1026-33.

7. Valsangiacomo Buechel ER, Grosse-Wortmann L, Fratz S, Eichhorn J, Sarikouch S, Greil GF, Beerbaum P, Bucciarelli-Ducci C, Bonello B, Sieverding L, Schwitter J, Helbing WA, Eacvi, Galderisi M, Miller O, Sicari R, Rosa J, Thaulow E, Edvardsen T, Brockmeier K, Qureshi S, Stein J. Indications for cardiovascular magnetic resonance in children with congenital and acquired heart disease: an expert consensus paper of the Imaging Working Group of the AEPC and the Cardiovascular Magnetic Resonance Section of the EACVI. Eur Heart J Cardiovasc Imaging 2015;16:281-97.

8. Selly JB, Iriart X, Roubertie F, Mauriat P, Marek J, Guilhon E, Jamal-Bey K, Thambo JB. Multivariable assessment of the right ventricle by echocardiography in patients with repaired tetralogy of Fallot undergoing pulmonary valve replacement: a comparative study with magnetic resonance imaging. Arch Cardiovasc Dis 2015;108:5-15.

9. van der Zwaan HB, Geleijnse ML, McGhie JS, Boersma E, Helbing WA, Meijboom FJ, Roos-Hesselink JW. Right ventricular quantification in clinical practice: twodimensional vs. three-dimensional echocardiography compared with cardiac magnetic resonance imaging. Eur J Echocardiogr 2011;12:656-64.

10. Simpson J, Lopez L, Acar P, Friedberg M, Khoo N, Ko H, Marek J, Marx G, McGhie J, Meijboom F, Roberson D, Van den Bosch A, Miller O, Shirali G. Three-dimensional echocardiography in congenital heart disease: an expert consensus document from the European Association of Cardiovascular Imaging and the American Society of Echocardiography. Eur Heart J Cardiovasc Imaging 2016;17:1071-97.

11. Laser KT, Karabiyik A, Korperich H, Horst JP, Barth P, Kececioglu D, Burchert W, DallaPozza R, Herberg U. Validation and Reference Values for Three-Dimensional Echocardiographic Right Ventricular Volumetry in Children: A Multicenter Study. J Am Soc Echocardiogr 2018;31:1050-63.

12. Vitarelli A, Mangieri E, Terzano C, Gaudio C, Salsano F, Rosato E, Capotosto L, D'Orazio S, Azzano A, Truscelli G, Cocco N, Ashurov R. Three-dimensional echocardiography and 2D-3D speckle-tracking imaging in chronic pulmonary hypertension: diagnostic accuracy in detecting hemodynamic signs of right ventricular (RV) failure. J Am Heart Assoc 2015;4:e001584.

13. Shimada YJ, Shiota M, Siegel RJ, Shiota T. Accuracy of right ventricular volumes and function determined by three-dimensional echocardiography in comparison with magnetic resonance imaging: a meta-analysis study. J Am Soc Echocardiogr 2010;23:943-53.

14. Khoo NS, Young A, Occleshaw C, Cowan B, Zeng IS, Gentles TL. Assessments of right ventricular volume and function using three-dimensional echocardiography in older children and adults with congenital heart disease: comparison with cardiac magnetic resonance imaging. J Am Soc Echocardiogr 2009;22:1279-88.

15. Laser KT, Horst JP, Barth P, Kelter-Klopping A, Haas NA, Burchert W, Kececioglu D, Korperich H. Knowledgebased reconstruction of right ventricular volumes using real-time three-dimensional echocardiographic as well as cardiac magnetic resonance images: comparison with a cardiac magnetic resonance standard. J Am Soc Echocardiogr 2014;27:1087-97.

16. Sheehan FH, Kilner PJ, Sahn DJ, Vick GW, 3rd, Stout KK, Ge S, Helbing WA, Lewin M, Shurman AJ, Buechel EV, Litt HI, Waiss MP. Accuracy of knowledge-based reconstruction for measurement of right ventricular volume and function in patients with tetralogy of Fallot. Am J Cardiol 2010;105:993-9.

17. Dragulescu A, Grosse-Wortmann L, Fackoury C, Riffle 
S, Waiss M, Jaeggi E, Yoo SJ, Friedberg MK, Mertens L. Echocardiographic assessment of right ventricular volumes after surgical repair of tetralogy of Fallot: clinical validation of a new echocardiographic method. J Am Soc Echocardiogr 2011;24:1191-8.

18. Bhave NM, Patel AR, Weinert L, Yamat M, Freed BH, Mor-Avi V, Gomberg-Maitland M, Lang RM. Threedimensional modeling of the right ventricle from twodimensional transthoracic echocardiographic images: utility of knowledge-based reconstruction in pulmonary arterial hypertension. J Am Soc Echocardiogr 2013;26:860-7.

19. Knight DS, Schwaiger JP, Krupickova S, Davar J, Muthurangu V, Coghlan JG. Accuracy and Test-Retest Reproducibility of Two-Dimensional KnowledgeBased Volumetric Reconstruction of the Right Ventricle in Pulmonary Hypertension. J Am Soc Echocardiogr 2015;28:989-98.

20. Trzebiatowska-Krzynska A, Driessen M, Sieswerda GT, Wallby L, Swahn E, Meijboom F. Knowledge-based 3D reconstruction of the right ventricle: comparison with cardiac magnetic resonance in adults with congenital heart disease. Echo Res Pract 2015;2:109-16.

21. Krell K, Laser KT, Dalla-Pozza R, Winkler C, Hildebrandt U, Kececioglu D, Breuer J, Herberg U. Real-Time Three-Dimensional Echocardiography of the Left Ventricle-Pediatric Percentiles and Head-to-Head Comparison of Different Contour-Finding Algorithms: A Multicenter Study. J Am Soc Echocardiogr 2018.

22. Cole TJ, Green PJ. Smoothing reference centile curves: the LMS method and penalized likelihood. Stat Med 1992;11:1305-19.

23. R Core Team. A language and environment for statistical computing. Vienna, Austria: R Foundation for Statistical Computing, 2016.

24. Rigby RA, Stasinopoulos DM. Generalized additive models for location, scale and shape. Journal of the Royal Statistical Society: Series C (Applied Statistics) 2005;54:507-54.

25. Ventetuolo CE, Ouyang P, Bluemke DA, Tandri H, Barr RG, Bagiella E, Cappola AR, Bristow MR, Johnson C, Kronmal RA, Kizer JR, Lima JA, Kawut SM. Sex hormones are associated with right ventricular structure and function: The MESA-right ventricle study. Am J Respir Crit Care Med 2011;183:659-67.

26. Bhatla P, Nielsen JC, Ko HH, Doucette J, Lytrivi ID, Srivastava $\mathrm{S}$. Normal values of left atrial volume in pediatric age group using a validated allometric model. Circ Cardiovasc Imaging 2012;5:791-6.
27. Sluysmans T, Colan SD. Theoretical and empirical derivation of cardiovascular allometric relationships in children. J Appl Physiol (1985) 2005;99:445-57.

28. Dewey FE, Rosenthal D, Murphy DJ, Jr., Froelicher VF, Ashley EA. Does size matter? Clinical applications of scaling cardiac size and function for body size. Circulation 2008;117:2279-87.

29. Sarikouch S, Peters B, Gutberlet M, Leismann B, KelterKloepping A, Koerperich H, Kuehne T, Beerbaum P. Sexspecific pediatric percentiles for ventricular size and mass as reference values for cardiac MRI: assessment by steadystate free-precession and phase-contrast MRI flow. Circ Cardiovasc Imaging 2010;3:65-76.

30. Sarikouch S, Boethig D, Beerbaum P. Gender-specific algorithms recommended for patients with congenital heart defects: review of the literature. Thorac Cardiovasc Surg 2013;61:79-84.

31. Kawut SM, Lima JA, Barr RG, Chahal H, Jain A, Tandri H, Praestgaard A, Bagiella E, Kizer JR, Johnson WC, Kronmal RA, Bluemke DA. Sex and race differences in right ventricular structure and function: the multi-ethnic study of atherosclerosis-right ventricle study. Circulation 2011;123:2542-51.

32. Maffessanti F, Muraru D, Esposito R, Gripari P, Ermacora D, Santoro C, Tamborini G, Galderisi M, Pepi M, Badano LP. Age-, body size-, and sex-specific reference values for right ventricular volumes and ejection fraction by three-dimensional echocardiography: a multicenter echocardiographic study in 507 healthy volunteers. Circ Cardiovasc Imaging 2013;6:700-10.

33. D'Oronzio U, Senn O, Biaggi P, Gruner C, Jenni R, Tanner FC, Greutmann M. Right heart assessment by echocardiography: gender and body size matters. J Am Soc Echocardiogr 2012;25:1251-8.

34. Zilberman MV, Khoury PR, Kimball RT. Twodimensional echocardiographic valve measurements in healthy children: gender-specific differences. Pediatr Cardiol 2005;26:356-60.

35. Scholz DG, Kitzman DW, Hagen PT, Ilstrup DM, Edwards WD. Age-related changes in normal human hearts during the first 10 decades of life. Part I (Growth): A quantitative anatomic study of 200 specimens from subjects from birth to 19 years old. Mayo Clin Proc 1988;63:126-36.

36. Kutty S, Li L, Polak A, Gribben P, Danford DA. Echocardiographic knowledge-based reconstruction for quantification of the systemic right ventricle in young adults with repaired D-transposition of great arteries. Am 
J Cardiol 2012;109:881-8.

37. Wheeler M, Leipsic J, Trinh P, Raju R, Alaamri S, Thompson CR, Moss R, Munt B, Kiess M, Grewal J. Right Ventricular Assessment in Adult Congenital Heart Disease Patients with Right Ventricle-to-Pulmonary Artery Conduits. J Am Soc Echocardiogr 2015;28:522-32.

38. Nyns EC, Dragulescu A, Yoo SJ, Grosse-Wortmann L. Evaluation of knowledge-based reconstruction for magnetic resonance volumetry of the right ventricle after arterial switch operation for dextro-transposition of the great arteries. Int J Cardiovasc Imaging 2016;32:1415-23.

39. Sugeng L, Mor-Avi V, Weinert L, Niel J, Ebner C, Steringer-Mascherbauer R, Bartolles R, Baumann R, Schummers G, Lang RM, Nesser HJ. Multimodality comparison of quantitative volumetric analysis of the right ventricle. JACC Cardiovasc Imaging 2010;3:10-8.

40. Smit F, Laser KT, DallaPozza R, Hildebrandt U, Breuer J, Kececioglu D, Herberg U. Real-Time 3D-Echocardiography of the Pediatric Right Ventricle - influence of different quantification software. Cardiol Young 2015:S67. Available online: http://www.uni-kiel.de/ aepc/2015/aepcAbstractsFinalPrint/MP4_2fin.pdf

Cite this article as: Herberg U, Smit F, Winkler C, Dalla-Pozza R, Breuer J, Laser KT. Real-time 3D-echocardiography of the right ventricle-paediatric reference values for right ventricular volumes using knowledge-based reconstruction: a multicentre study. Quant Imaging Med Surg 2021;11(7):2905-2917. doi: 10.21037/qims-20-1155
41. Lopez L, Colan S, Stylianou M, Granger S, Trachtenberg F, Frommelt P, et al. Relationship of Echocardiographic Z Scores Adjusted for Body Surface Area to Age, Sex, Race, and Ethnicity: The Pediatric Heart Network Normal Echocardiogram Database. Circ Cardiovasc Imaging 2017;10:e006979.

42. Jenkins C, Chan J, Bricknell K, Strudwick M, Marwick TH. Reproducibility of right ventricular volumes and ejection fraction using real-time three-dimensional echocardiography: comparison with cardiac MRI. Chest 2007;131:1844-51.

43. Grewal J, Majdalany D, Syed I, Pellikka P, Warnes CA. Three-dimensional echocardiographic assessment of right ventricular volume and function in adult patients with congenital heart disease: comparison with magnetic resonance imaging. J Am Soc Echocardiogr 2010;23:127-33.

44. Medvedofsky D, Addetia K, Patel AR, Sedlmeier A, Baumann R, Mor-Avi V, Lang RM. Novel Approach to Three-Dimensional Echocardiographic Quantification of Right Ventricular Volumes and Function from Focused Views. J Am Soc Echocardiogr 2015;28:1222-31. 

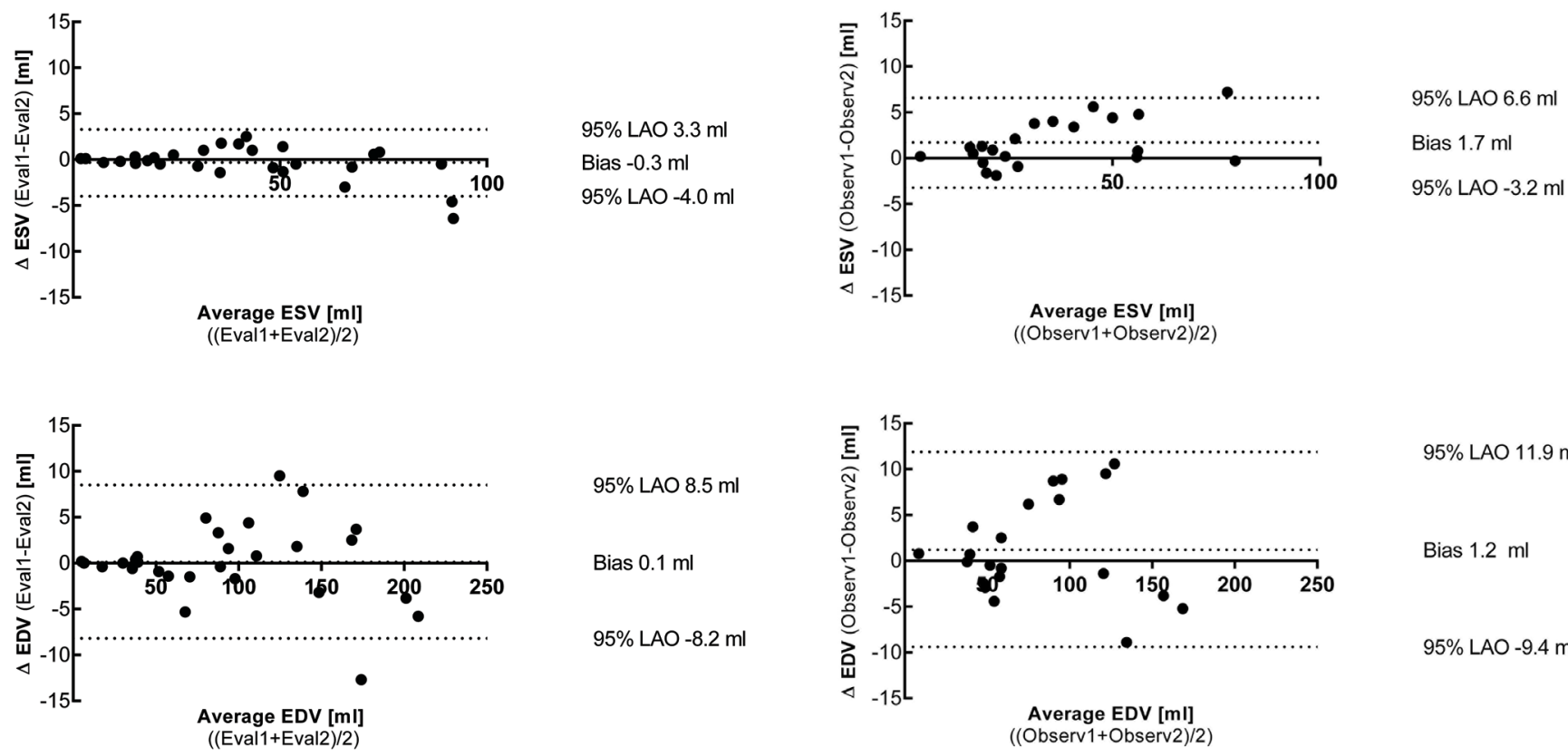

$95 \%$ LAO $8.5 \mathrm{ml}$

Bias $0.1 \mathrm{ml}$

$95 \%$ LAO $-8.2 \mathrm{ml}$

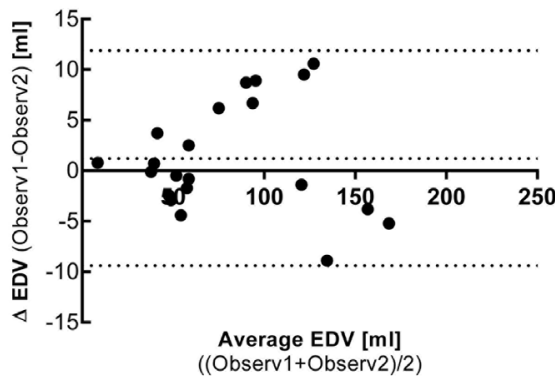

$95 \%$ LAO $11.9 \mathrm{~m}$

Bias $1.2 \mathrm{ml}$

$95 \%$ LAO $-9.4 \mathrm{ml}$

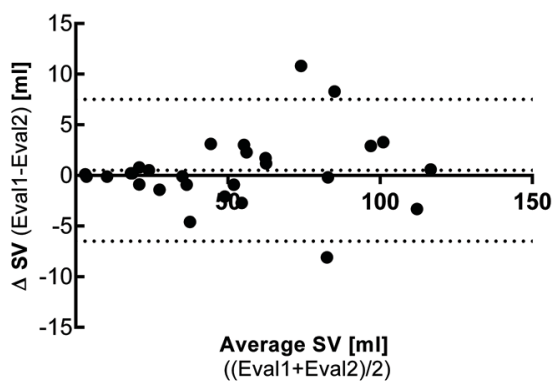

$95 \%$ LAO $7.5 \mathrm{ml}$

Bias $0.5 \mathrm{ml}$

$95 \%$ LAO $-6.5 \mathrm{ml}$

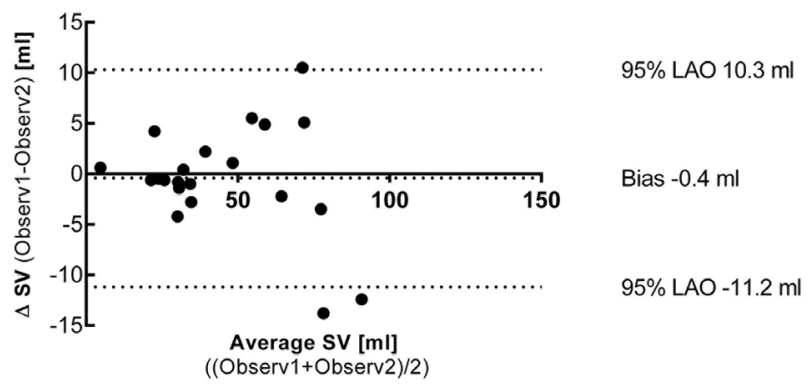

Figure S1 Intra-observer variability. Bland-Altman plots for EDV, ESV, and SV with biases and 95\% LOA. EDV, end diastolic volume; EF, ejection fraction; ESV, end systolic volume; SV, stroke volume; LOA, limits of agreement.

Figure S2 Inter-observer variability. Bland-Altman plots for EDV, ESV, and SV with biases and 95\% LOA. EDV, end diastolic volume; EF, ejection fraction; ESV, end systolic volume; SV, stroke volume; LOA, limits of agreement. 

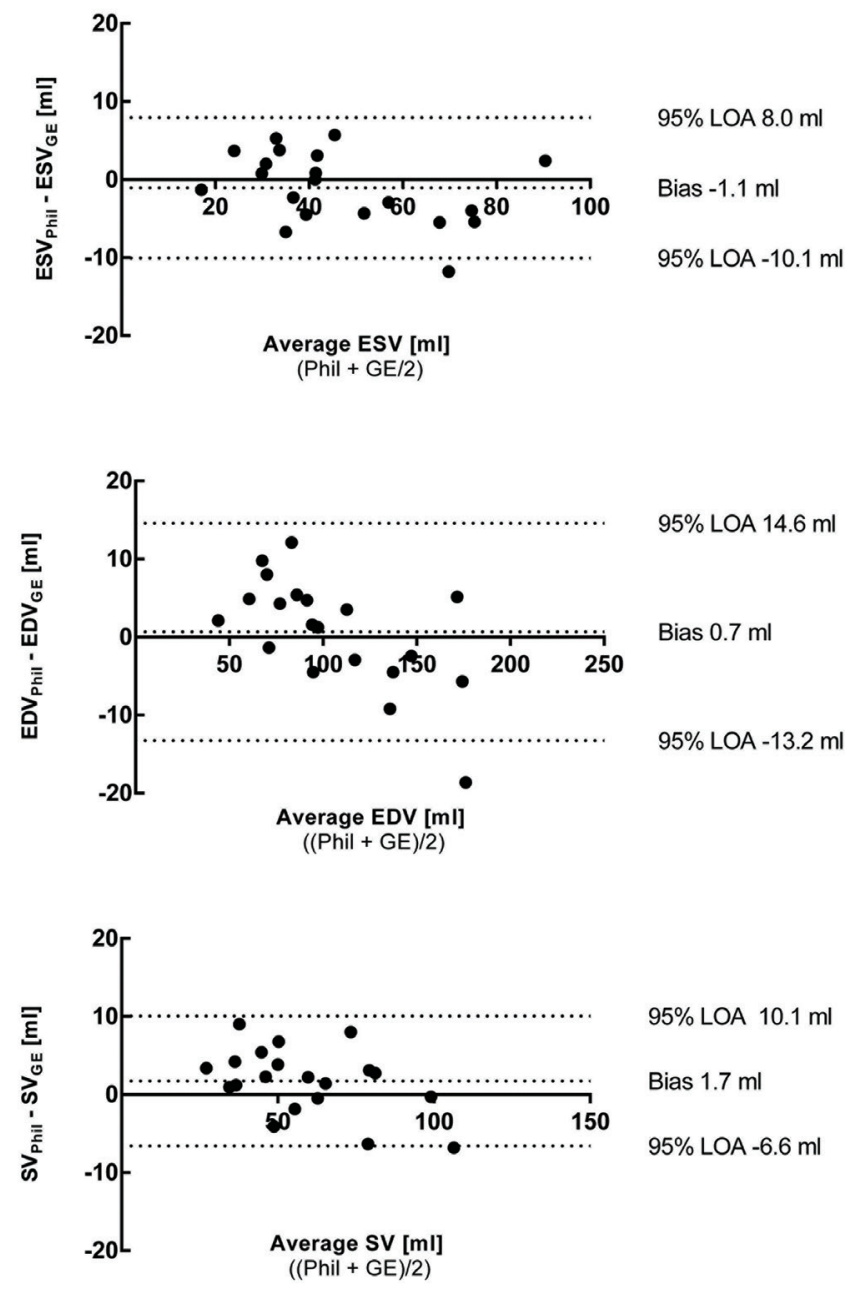

Figure S3 Intra-vendor variability, comparing Philips and GE datasets-Bland-Altman plots for EDV, ESV, and SV with biases and 95\% LOA. EDV, end diastolic volume; EF, ejection fraction; ESV, end systolic volume; SV, stroke volume; LOA, limits of agreement.

$95 \%$ LOA $-13.2 \mathrm{ml}$
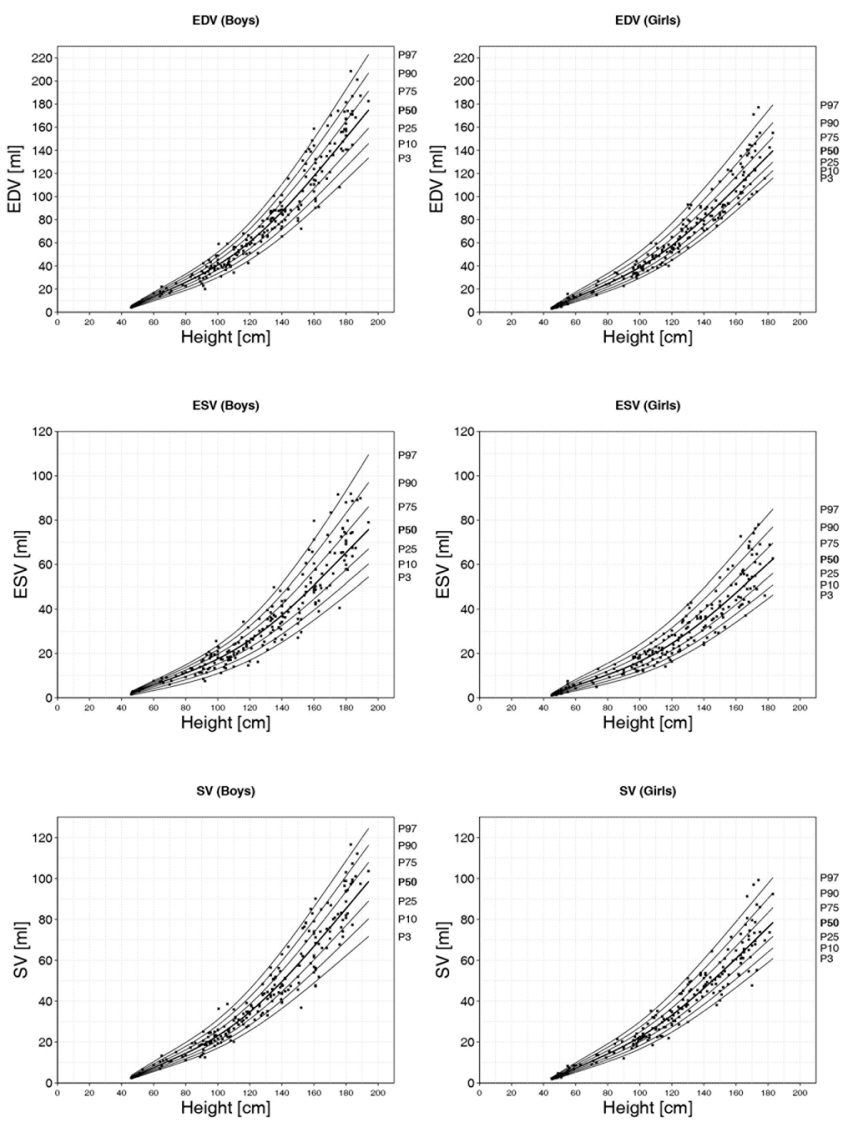

Figure S4 Gender-specific percentiles for with EDV, ESV, and $\mathrm{SV}$ in relation to height. $\mathrm{P}$ indicates the percentile value, e.g., P50 $=50$ th percentile value. $\mathrm{EDV}$, end diastolic volume; EF, ejection fraction; ESV, end systolic volume; SV, stroke volume; LOA, limits of agreement. 